\section{Kidney \\ Blood Pressure \\ Research}

Review

\title{
Chronic Renal Disease and Risk of Cardiovascular Morbidity-Mortality
}

\author{
Antonio Santoro ${ }^{a}$ Marcora Mandreolib \\ aDepartment of Nephrology, Dialysis and Hypertension Azienda Ospedaliero-Universitaria di Bologna,

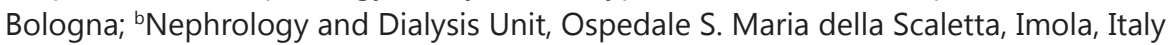

\author{
Kay Words \\ Cardiovascular disease $•$ Chronic Kidney Disease $•$ Proteinuria $•$ CKD $•$ CV risk
}

\begin{abstract}
The pathogenesis of cardiovascular disease in CKD differs subtly from that of non-CKD patients. As renal function declines, the role and impact of treating classical risk factors may change and diminish. However, hypertension, hypercholesterolaemia and smoking cessation management should be optimized and may require multiple agents and approaches, particularly as CKD advances. Hypertension treatment would appear to be one management area in which performance is less than ideal. Moreover there are mechanisms and risk factors that are specific to $C K D$, capable of triggering a vascular pathology and that justify the surplus of CV morbidity in CKD patients and that require we consider CKD as a CV risk factor per se. In the initial stages of CKD it would be advisable to implement all the preventative measures to stem the onset of CV disease, whereas in the more advanced stages a multifactorial approach is likely to be necessary, as we have learned from the STENO-study within the diabetes.
\end{abstract}

Copyright $@ 2014$ S. Karger AG, Basel

\section{Introduction}

In 1836 Richard Bright was the first to describe the association between CKD and cardiovascular diseases. However, only recently has it been understood that cardiovascular events are the major cause of death in Chronic Kidney Disease (CKD). Individuals with CKD have a substantially greater risk of cardiovascular disease compared with the general population but they have largely been excluded from clinical trials. Between the heart and the kidney there is a complex bi-directional relationship where damage to one of the two organs leads to the dysfunction of the other in a sort of vicious circle, which ultimately determines the amplification of the damage in both organs. 


\section{Kidney Blood Pressure Research}

\section{The epidemiology of cardiovascular risk in CKD}

Chronic Kidney Disease affects a significant quota of the population and is characterized by progression towards terminal uremia, with the need for replacement treatment by means of dialysis or transplantation. In 2004 the work of Keith, who followed a population of patients with CKD for several years, showed that CKD patients had a higher likelihood of death, above all for cardiovascular causes (CV), rather than reaching the final phase of the disease with the need for dialysis [1]. Many studies both in the general population [2] and in patient cohorts $[3,4]$ agree in reporting this association between renal dysfunction and excessive mortality for all the causes and in particular for excess of CV morbidity. The increased risk goes hand in hand with the progressive decline in renal function. Two recent meta-analyses that have taken into consideration as CKD expression the simultaneous presence of albuminuria, and the reduction of the glomerular filtration rate (GFR), have considered the relationship between renal damage and CV risk in over 30 cohorts for a total of around 1,400,000 subjects [5, 6]. After adjusting for the traditional CV risk factors and for albuminuria, they demonstrated that the CV mortality increases in a linear way as GFR is reduced, starting from values lower than $75 \mathrm{ml} / \mathrm{min}[5,6]$. As compared with normal subjects, the patients with stage 3 CKD double their CV mortality risk, while patients with stage 4 CKD have a risk three times greater. While for the glomerular filtrate there is a threshold value $(75-60 \mathrm{ml} / \mathrm{min})$ that discriminates the risk, the association between $\mathrm{CV}$ risk and microalbuminuria has a linear trend. Even values of albumin to creatinine ratio at the upper limits of the norm $(30 \mathrm{mg} / \mathrm{g})$ involve an increase in CV mortality $[5,6]$ and thus modest increases in microalbuminuria warrant further clinical analysis. Moreover, the fact that there might be a continuum between microalbuminuria and the risk of presenting CV events had already been evidenced in the general population in the PREVEND study [7]. Thus, increased levels of urinary albumin excretion confer an increased CVD risk across all ranges of GFR, regardless of how urine albumin excretion is assessed.

The presence of CKD is associated with a broad spectrum of cardiovascular diseases such as stroke [8], peripheral arteriopathy [9] and atrial fibrillation [10], but above all coronary disease [11, 12] and cardiac insufficiency [13]. Also, the presence of CKD complicates and worsens the prognosis of patients with acute myocardial infarction [14] with the need for coronary revascularization [15].

Diabetes and arterial hypertension are the main causes that lead to CKD, but also represent per se a risk factor for CV diseases. For a long time it was thought that the surplus of CV risk observed in patients with CKD was the result of these two underlying pathologies. Contrariwise, two further recent meta-analyses of the Chronic Kidney Disease Prognosis Consortium $[16,17]$ clearly show that the reduction in GFR and albuminuria are already CV risk factors per se, irrespective of the presence of hypertension and diabetes. Also, Tonelli et al [12], examining a large dataset that included subjects of the Alberta Kidney Disease Network without previous Myocardial Infarction (MI) has shown that the presence of CKD without diabetes confers a greater risk of MI than diabetes alone [12] and thus also CKD can be considered as an equivalent and independent coronary risk factor. The Authors conclude that CKD could be added to the list of criteria defining people at the highest risk of future coronary events [12].

\section{Risk factors and pathogenetic mechanisms}

Even if the risk factors and the pathophysiological mechanisms that bind CKD to CV disease are not yet wholly understood, and the weight that each one can have in the various CKD stages is not clear, some general considerations can nonetheless be formulated to account for the surplus of CV morbidity and mortality observed in CKD patients: 


\section{Kidney \\ Blood Pressure Research}

a) CKD often coexists with other traditional CV risk factors, such as dyslipidaemia, smoking, obesity, hypertension and diabetes.

b) In the initial stages of CKD, renal dysfunction could simply reflect a subclinical vascular damage that has not yet appeared in other target-organs.

c) CKD patients are very often undertreated with drugs of proven efficacy in reducing CV risk.

d) It is possible that the therapies that have resulted to be effective in the general population or in other settings are not as effective in the course of CKD.

Framingham's traditional cardiovascular risk factors are highly represented in patients with CKD, but alone they are not sufficient to justify the excess CV morbidity [18] and the reduced life expectancy. Alongside age, hypertension, diabetes, obesity and dyslipidaemia, we find non-traditional factors (endothelial dysfunction tied with an excess of inducers of inflammation/oxidation, anaemia, alterations of mineral metabolism and vascular calcifications, hyperactivity of the sympathetic system) and factors closely related to renal insufficiency strictly speaking (volume expansion, new uremic toxins). The latter seem to have a pre-eminent role in the more advanced phases of CKD. It is likely that traditional and non-traditional factors do not act separately, but that there exists a continuous interplay and that the prevalence of one upon the other may vary depending on the disease stage and the age of the patients. Traditional and non-traditional risk factors may negatively act in conditioning either vascular damage or heart muscle damage (Figure 1).

Fig. 1. Pathogenesis of vascular and myocardial damage in CKD patients (IHD Ischemic heart disease, PVD peripheral vascular disease).

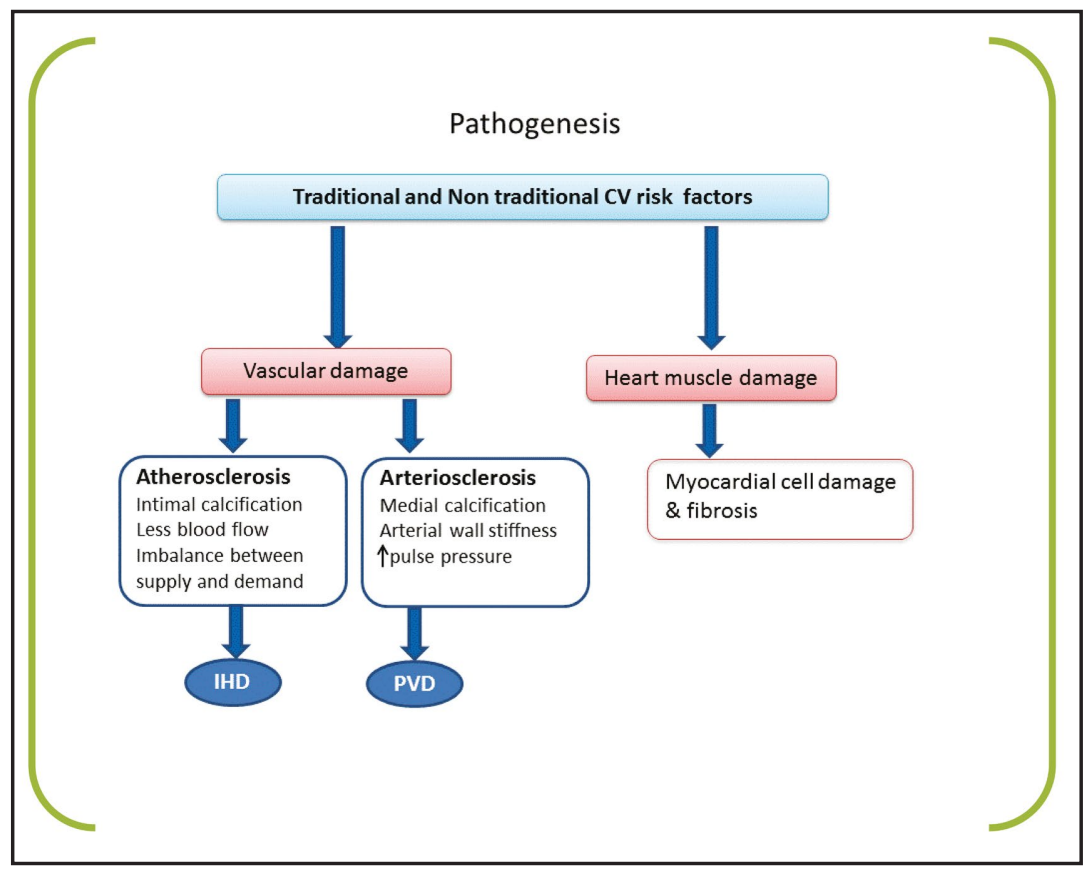

\section{Conclusions}

Many epidemiological studies above all in these past few years have confirmed the association between CV diseases and CKD, but above all they have allowed us to establish that the bond between the two pathologies is not solely due to the fact that many risk factors (smoke, obesity, hypertension, dyslipidaemia and diabetes) are in common or simply reflects a longer duration or severity of traditional CVD risk factors. There is evidence to support 


\section{Kidney \\ Blood Pressure Research}

both blood pressure and cholesterol reduction in the CKD population. However, there are mechanisms and risk factors that are specific to CKD, capable of triggering a vascular pathology and that justify the surplus of CV morbidity in CKD patients and that require we consider CKD as a CV risk factor per se. Despite this understanding, the CV diseases in CKD patients are often inadequately investigated and end up being underestimated. The risk of bleeding with antiplatelet drugs is high in CKD and these should be used with due caution. Although there has been recent interest in targeting non-classical cardiovascular risk factors in CKD, few trials have demonstrated any significant reduction in cardiovascular risk. Smoking cessation remains important but is poorly studied in CKD with many dialysis patients still smoking. Future work should focus on new management strategies and drug combinations that tackle the classical risk factors as well as better designed longitudinal and randomized controlled trials aimed at non-classical risk factors. Patients with CKD should be included in all cardiovascular intervention studies, given their poor outcomes without interventions.

\section{Disclosure Statement}

The authors of this manuscript state that they do not have any conflict of interests and nothing to disclose.

\section{References}

1 Keith DS, Nichols GA, Gullion CM, Brown JB, Smith DH: Longitudinal follow-up and outcomes among a population with chronic kidney disease in a large managed care organization. Arch Intern Med 2004;164:659-663.

-2 Go AS, Chertow GM, Fan D, McCulloch CE, Hsu CY: Chronic kidney disease and the risks of death, cardiovascular events, and hospitalization. N Engl J Med 2004;351:1296-1305.

-3 Schillaci G, Reboldi G, Verdecchia P: High-normal serum creatinine concentration is a predictor of cardiovascular risk in essential hypertension. Arch Intern Med 2001;161:886-891.

-4 Mann JF, Gerstein HC, Pogue J, Bosch J, Yusuf S: Renal Insufficiency as a Predictor of Cardiovascular Outcomes and the Impact of Ramipril: The HOPE Randomized Trial. Ann Intern Med 2001;134:629-636.

-5 Matsushita K, van der Velde M, Astor BC, Woodward M, Levey AS, de Jong PE, Coresh J, Gansevoort RT for the CKD Prognosis Consortium: Association of estimated glomerular filtration rate and albuminuria with all-cause and cardiovascular mortality in general population cohorts: a collaborative meta-analysis. Lancet 2010;375:2073-2081.

6 van der Velde M, Matsushita K, Coresh J, Astor BC, Woodward M, Levey A, de Jong P, Gansevoort RT; Chronic Kidney Disease Prognosis Consortium: Lower estimated glomerular filtration rate and higher albuminuria are associated with all-cause and cardiovascular mortality. A collaborative meta-analysis of high-risk population cohorts. Kidney Int 2011;79:1341-1352.

7 Hillege HL, Fidler V, Diercks GF, van Gilst WH, de Zeeuw D, van Veldhuisen DJ, Gans RO, Janssen WM, Grobbee DE, de Jong PE: Prevention of Renal and Vascular End Stage Disease (PREVEND) Study Group. Urinary albumin excretion predicts cardiovascular and noncardiovascular mortality in general population. Circulation 2002;106:1777-1782.

-8 Abramson JL, Jurkovitz CT, Vaccarino V, Weintraub WS, McClellan W: Chronic kidney disease, anemia, and incident stroke in a middle-aged, community-based population: the ARIC study. Kidney Int 2003;64:610615.

-9 Wattanakit K, Folsom AR, Selvin E, Coresh J, Hirsch AT, Weatherley BD: Kidney function and risk of peripheral arterial disease: results from the Atherosclerosis Risk In Communities (ARIC) study. J Am Soc Nephrol 2007;18:629-636. 


\section{Kidney \\ Blood Pressure Research}

Kidney Blood Press Res 2014;39:142-146

\begin{tabular}{l|l}
\hline DOI: $10.1159 / 000355789$ & (c 2014 S. Karger AG, Basel
\end{tabular}

Published oniıne: July 29, 2014

www.karger.com/kbr

10 Alonso A, Lopez FL, Matsushita K, Loehr LR, Agarwal SK, Chen LY, Soliman EZ, Astor BC, Coresh J:Chronic kidney disease is associated with the incidence of atrial fibrillation: the Atherosclerosis Risk In Communities (ARIC) study. Circulation 2011;123:2946-2953.

11 Astor BC, Coresh J, Heiss G, Pettitt D, Sarnak MJ: Kidney function and anemia as risk factors for coronary heart disease and mortality: the Atherosclerosis Risk In Communities (ARIC) study. Am Heart J 2006;151:492-500.

12 Tonelli M, Muntner P, Lloyd A Manns BJ, Klarenbach S, Pannu N, James MT, Hemmelgarn BR, for the Alberta Kidney Disease Network: Risk of coronary events in people with chronic kidney disease compared with those with diabetes: a population-level cohort study. Lancet 2012;380:807-814.

-13 Kottgen A, Russell SD, Loehr LR, Crainiceanu CM, Rosamond WD, Chang PP, Chambless LE, Coresh J: Reduced kidney function as a risk factor for incident heart failure: the Atherosclerosis Risk In Communities (ARIC) study. J Am Soc Nephrol 2007;18:1307-1315.

14 Anavekar NS, McMurray JJ, Velazquez EJ, Solomon SD, Kober L, Rouleau JL, White HD, Nordlander R, Maggioni A, Dickstein K, Zelenkofske S, Leimberger JD, Califf RM, Pfeffer MA: Relation between renal dysfunction and cardiovascular outcomes after myocardial infarction. N Engl J Med 2004;351:1285-1295.

15 Dohi T, Miyauchi K, Okazaki S, Yokoyama T, Tamura H, Kojima T, Yokoyama K, Kurata T, Daida H: Long-term impact of mild chronic kidney disease in patients with acute coronary syndrome undergoing percutaneous coronary interventions. Nephrol Dial Transplant 2011;26:2906-2911.

-16 Fox CS, Matsushita K, Woodward M, Bilo HJ, Chalmers J, Heerspink HJ, Lee BJ, Perkins RM, Rossing P, Sairenchi T, Tonelli M, Vassalotti JA, Yamagishi K, Coresh J, de Jong PE, Wen CP, Nelson RG; Chronic Kidney Disease Prognosis Consortium: Associations of kidney disease measures with mortality and end-stage renal disease in individuals with and without diabetes: A meta-analysis of 1024977 individuals. Lancet 2012;380:1662-1673.

17 Mahmoodi BK, Matsushita K, Woodward M, Blankestijn PJ, Cirillo M, Ohkubo T, Rossing P, Sarnak MJ, Stengel B, Yamagishi K, Yamashita K, Zhang L, Coresh J, de Jong PE, Astor BC; Chronic Kidney Disease Prognosis Consortium: Associations of kidney disease measures with mortality and end-stage renal disease in individuals with and without hypertension: a meta-analysis. Lancet 2012;380:1649-1661.

18 Schiffrin EL, Lipman ML, Mann JFE: Chronic Kidney Disease Effects on the Cardiovascular System. Circulation 2007;116:85-97. 